\section{Edycaçäa

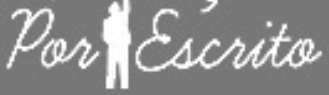

ARTIGO

\section{Editor}

Alexandre Anselmo Guilherme PUCRS, RS, Brasil

\section{Editor Assistente}

Cibele Cheron

PUCRS, RS, Brasi

\section{Editores Associados}

Bruno Antonio Picoli

Universidade Federal da Fronteira Sul, Chapecó, SC, Brasil

Pricila Kohls dos Santos Universidade Católica de Brasília, Brasília, DF, Brasil

Renato de Oliveira Brito

Universidade Católica de Brasilia, Brasilia, DF, Brasil

Elisa Ustarroz

PUCRS, Porto Alegre, RS, Brasil

\section{ISSN 2179-8435}

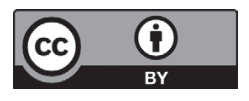

Este artigo está licenciado sob forma de uma licença Creative Commons Atribuição 4.0 Internacional, que permite uso irrestrito, distribuiçăa e reproduçãa em qualquer meio, desda
seja corretamente citada hitp://creativecommons.org/licenses/by/4.0/deed.pt_BP

\title{
Os sentidos do ensino de Filosofia no Ensino Médio: uma abordagem fenomenológica
}

\author{
The senses of teaching Philosophy in High School: a phenomenological approach
}

\author{
Williams Nunes da Cunha Junior (1) \\ Universidade Federal de Alagoas (UFAL), Maceió, AL, Brasil.
}

\section{RESUMO}

O presente artigo apresenta os resultados obtidos em nossa pesquisa realizada junto ao grupo de estudos Filosofia e Educação/Ensino de Filosofia, do Programa de Pós-Graduação em Educação da Universidade Federal de Alagoas (UFAL). O objetivo de nossa investigação foi compreender os sentidos que professores e alunos detêm sobre a prática do ensino de Filosofia na qual esses sujeitos estão inseridos. Por meio do método fenomenológico aplicado à pesquisa, descrito por Moreira (2002), realizamos entrevistas das quais recolhemos um conjunto de assertivas significativas com as quais desenvolvemos nosso trabalho. O sentido do ensino de Filosofia aparece nas falas dos sujeitos de nossa pesquisa como compreensão do mundo, como um saber mais, uma abertura para o conhecimento, como capacidade de buscar conhecimentos. Entende-se ainda que esse ensino tem o potencial de auxiliar os estudantes a crescerem pessoalmente e fazerem escolhas mais acertadas. A pesquisa sobre os sentidos do ensino de Filosofia encontra a sua razão de ser na contribuição que pode oferecer para a formação dos futuros professores e professoras de Filosofia, trazendo novos elementos para pensar e repensar constantemente a nossa prática.

Palavras-chave: Ensino de Filosofia. Sentido. Educação.

\section{ABSTRACT}

The present article presents the results obtained in our research carried out with the Philosophy and Education/ Teaching of Philosophy group of the Post-Graduate Program in Education, Federal University of Alagoas. The objective of our investigation was to understand the sense that teachers and stundents hold on the practice of the teaching of Philosophy in wich these subjects are inserted. Through the phenomenological method applied to research, described by Moreira (2002), we conducted interviews from which we collected a set of significant assertions with which we developed our work. The sense of teaching Philosophy appears in the speeches of the subjects surveyed as an understanding of the world, as a knowledge, an opening to knowledge, as a capacity to seek knowledge. It is also understood that such teaching has the potential to help students grow personally and make better choices. The research on the sense of teaching Philosophy finds its reason in the contribution it can offer to the training of future professors of Philosophy, bringing new elements to think and constantly rethink our practice. Keywords: Teaching of Philosophy. Sense. Education. 


\section{Introdução}

presente pesquisa surge de nossa inquietação cotidiana a respeito do ensino de Filosofia, inquietação essa que

nasce de nossa prática docente com essa disciplina no Ensino Médio. Todos os dias, após os turnos vespertinos e noturnos de aula, a pergunta sobre o sentido do ensino de Filosofia para nós professores, mas também para aqueles a quem se destina nosso trabalho docente, nos inquietava.

A partir desses questionamentos decidimos tornar as nossas indagações em problema acadêmico a ser tratado em pesquisa de nível de mestrado. Esse torna-se, então, o problema central de nosso trabalho: qual o sentido de ensinar Filosofia para nós enquanto docentes? E, também, qual o sentido do ensino de Filosofia na vida daqueles jovens estudantes do Ensino Médio?

A questão do sentido sobre o ensino de Filosofia traz consigo uma dimensão ética importante. Agimos diante das coisas de acordo com os sentidos que elas possuem para nós. Os sentidos são capazes de nos mobilizar - ou não - diante das coisas que nos aparecem à consciência, isto é, diante dos fenômenos - posto que fenômeno é tudo aquilo que nos aparece à consciência.

O sentido pode ser pensando de diversas formas, como cuidado, sentir, rumo, destino e compreensão. Além do mais, a pergunta sobre o sentido é uma questão que nenhum professor deve deixar de fazer. Assim sendo, no primeiro momento de nosso texto trazemos uma discussão, ainda que sucinta, para pensar o sentido enquanto conceito e, também, como aquele se faz presente nos discursos oficiais sobre o ensino de Filosofia.

A compreensão dos sentidos que alunos e professores produzem sobre o ensino de Filosofia exige de nós adentrar à experiência vivida dos sujeitos de nossa pesquisa, em seu dia a dia com essa prática escolar. A fim de obter um resultado mais acertado para o que nos propomos, escolhemos por adotar o método fenomenológico aplicado à pesquisa, uma vez que esse seria o mais adequado para lidar com essas experiências.

O segundo tópico de nosso texto faz, então, uma explicação do método utilizado, entendendo que quando aplicado à pesquisa empírica, ele possui diversas adaptações, sendo a variante de Colaizzi (1978), descrita em Moreira (2002), a que utilizamos no presente trabalho.

O texto prossegue com a apresentação dos resultados de nossa pesquisa, apresentando o contexto em que ela está inserida e, em seguida, as assertivas ou conjunto de temas que nos foi permitido extrair das entrevistas realizadas com professores e alunos, unindo a isso uma discussão sobre esses conjuntos de temas a partir do que dizem os especialistas sobre o ensino de Filosofia.

A pesquisa foi desenvolvida na cidade de Rio Largo, Alagoas, em duas escolas públicas da rede estadual de ensino, com alunos da segunda e terceira séries do Ensino Médio. O período da pesquisa teve duração 
aproximada de três meses, contendo seis perguntas direcionadas aos professores e quatro direcionadas aos alunos.

A realização da pesquisa nos permitiu compreender a importância do ensino de Filosofia para a vida dos jovens estudantes, bem como para a dos próprios professores, uma vez que esse ensino contribui para pensar, pensar o novo e para saber mais.

\section{Para pensar o sentido}

A pergunta pelo sentido do ensino de Filosofia decorre de nossa própria prática como docentes dessa disciplina no Ensino Médio. Segundo Cerletti (2008), a questão do sentido é a questão primordial a qual o professor deveria se colocar e com rigor. Sendo assim, colocamo-nos essa questão, fazendo dela o centro de nossa pesquisa.

O sentido possui em si uma dimensão ética, uma vez que nós agimos com relação às coisas tendo por base os sentidos que tais coisas têm para nós (MOREIRA, 2002). Os sentidos que atribuímos a tudo o que nos cerca determina nosso modo de agir. Se algo não possui sentido para nós, talvez assumamos diante desse algo uma postura de indiferença ou rejeição.

A questão sobre o sentido do ensino de Filosofia não seria diferente do que foi afirmado anteriormente. Conforme Ghedin (2009, p. 23) "para fazer uma escolha pela Filosofia, é necessário o jovem e a sociedade da qual faz parte terem a oportunidade de saber o que ela é, qual a sua proposta, seus sentidos, seus significados humanos e quais problemas procurou e procura responder".

É necessário conhecer o sentido que a Filosofia e seu ensino possuem. Se assumirmos a dimensão ética dos sentidos, devemos compreender que nosso agir em relação ao ensino de Filosofia dependerá do sentido que atribuímos a ele. Assim sendo, torna-se necessário contribuir para que os alunos encontrem sentido nesse ensino, pois é dessa construção de sentido que dependerá a aprendizagem (GHEDIN, 2009).

Ao pensar o sentido, Sodelli (2008, p. 211, grifo do autor) aponta que "[...] sentido refere-se, primordialmente, ao modo peculiar do ser humano cuidar e sentir as coisas do mundo". Aqui aparece-nos uma dimensão afetiva do sentido. O cuidado, como modo de ser mais próprio do ser-aí1, ao lado da angústia, desempenham um papel importante para a perspectiva de fuga da decadência do homem.

\footnotetext{
1 O termo ser-aí, por nós utilizado, possui sua significação na tradição filosófica heideggeriana. Ser-aí seria a tradução portuguesa do termo "Dasein", em alemão, utilizado por Heidegger em sua obra "Ser e Tempo", para - podemos dizer de forma simplificada - designar o ser existente que é o homem.
} 
A pergunta poderia ser retomada aqui da seguinte forma: como professores e alunos cuidam e sentem o ensino de Filosofia? Ao que nos parece, a reformulação da pergunta nesses termos, leva-nos a compreensão de que os sentidos estão muito além de uma simples significação linguística ou gramatical.

Ainda em Sodelli (2008, p. 212, grifo do autor), encontramos que o "Sentido representa, por um lado, uma direção para a qual estamos nos dirigindo, um ponto no qual queremos chegar, um destino, um rumo e, por outro lado, o modo como nos direcionamos para este horizonte, o modo como nos sentimos nesta direção".

A dimensão de orientação, vista no segundo capítulo, reaparece aqui. Poderíamos mais uma vez reformular a questão inicial: qual a direção que professores e alunos dão ao ensino de Filosofia, ou para qual direção, para qual destino, para que rumo o ensino de Filosofia os conduz, ou ainda, como se sentem professores e alunos no caminhar do ensino de Filosofia?

Em Ser e Tempo, Heidegger (2005, p. 208), define o sentido como "aquilo em que se sustenta a compreensibilidade de uma coisa. Chamamos de sentido aquilo que pode articular-se na abertura da compreensão". Assim sendo, poderíamos recolocar mais uma vez a questão: como professores e alunos compreendem o ensino de Filosofia?

A compreensão do que se entende por sentido nos leva a entendê-lo dessa forma: cuidado, sentir, rumo, destino, compreensão. Todos os conceitos apresentados abarcam aquilo que entendemos como sentido. Antes de chegar no sentido que os professores e alunos envolvidos com essa prática possuem, vamos compreender como tal questão se apresenta nos discursos oficiais acerca do ensino de Filosofia.

\section{O sentido no discurso oficial}

O sentido do ensino de Filosofia - em todas as formas que aqui entendemos - parece ter sido, na história da educação brasileira, negligenciado. As idas e vindas, o movimento pendular obrigatoriedade e não obrigatoriedade marcam a falta de cuidado, de compreensão, de sentimento e de rumo para com o ensino de Filosofia.

A lei que tornou obrigatória a presença da Filosofia nos currículos das escolas de Ensino Médio não durou nem mesmo uma década. Já em 2017, tivemos a aprovação da alteração da Lei de Diretrizes e Bases da Educação Nacional (LDBEN), retirando a obrigatoriedade do ensino de Filosofia no Ensino Médio e dissolvendo-a como um conteúdo marginal.

O rumo da Filosofia no currículo até então é incerto. Poderíamos falar de uma ausência de sentido? Ao que parece, para aqueles que formulam as políticas educacionais de nosso País, não há mesmo sentido no ensino de Filosofia nesta etapa da educação básica. O que importa é apenas capacitar mão de obra para o mercado de trabalho. $\mathrm{E}$ a filosofia serve para isso? 
As Orientações Curriculares Nacionais (OCN's) para o ensino de Filosofia (2006) apontam como sentido do ensino de Filosofia a contribuição para o pleno desenvolvimento do educando, o que passa pela formação para a cidadania (BRASIL, 2006). O sentido enquanto cuidado passa pela garantia de recursos materiais e humanos que possibilitem as condições adequadas para que a Filosofia se estabeleça como uma disciplina no Ensino Médio.

As condições adequadas, segundo as próprias orientações, passam pela qualificação dos profissionais que atuam nessa etapa da educação básica. E essa qualificação exige uma formação profissional específica, isto é, os professores de Filosofia no Ensino Médio devem possuir formação na área. "Caso contrário, ela se tornaria uma vulgarização perigosa de boas intenções que só podem conduzir a péssimos resultados” (BRASIL, 2006, p. 17). Como vimos anteriormente, essa dimensão do sentido ainda aparece de modo muito carente, uma vez que profissionais com outras formações têm assumido o ensino dessa disciplina.

O sentido enquanto compreensão também aparece nas OCN's para o ensino de Filosofia. É necessário compreender a importância que a Filosofia possui na formação dos estudantes, com seu papel formador. Essa dimensão do sentido nos parece também prejudicada, pois a carga horária suficiente de duas horas-aula semanais, propostas pelas Orientações, não são cumpridas, pelo menos aqui em Alagoas, com exceção do ensino de tempo integral.

A dimensão de cuidado e compreensão do sentido, parece-nos carente, quando a Filosofia, por exemplo, é tratada por gestores como uma disciplina marginal, quando se cria uma hierarquização das disciplinas, na qual a Filosofia é colocada bem abaixo das demais, oferecendo a sensação de que ela só está no currículo para preencher o tempo dos alunos ou os horários desses na escola. Nem mesmo os gestores e coordenadores parecem compreender a importância da Filosofia na escola, na formação dos estudantes, algo que merece a nossa atenção.

O sentido enquanto compreensão aparece novamente nas OCN's no tópico em que se trata da identidade da Filosofia. Segundo Sardi (2008, p. 194 apud RODRIGUES, 2014, p. 35), "toda concepção acerca do ensinar-aprender filosofia remonta a uma problematização sobre o sentido da filosofia ou sobre o que é a filosofia". Dito isso, pensar sobre o sentido, e o sentido como compreensão, torna-se importante para um desenvolvimento satisfatório sobre o ensino de Filosofia. Temos diante de nós "um primeiro e permanente problema filosófico" (BRASIL, 2006, p. 21), ainda que o mesmo não possa ser resolvido integralmente.

Ainda no que diz respeito ao sentido como compreensão, os conhecimentos de Filosofia devem ser para os estudantes "vivos e adquiridos como apoio para a vida, pois do contrário dificilmente teriam sentido para um jovem nessa fase de formação" (BRASIL, 2006, p. 28). Mais uma vez a questão do sentido aparece como importante para o bom desenvolvimento do ensino de Filosofia no Ensino Médio. 
Enquanto rumo, isto é, onde queremos chegar com o ensino de Filosofia, as OCN's apontam algumas capacidades que os estudantes podem adquirir

Trata-se da criatividade, da curiosidade, da capacidade de pensar múltiplas alternativas para a solução de um problema, ou seja, do desenvolvimento do pensamento crítico, da capacidade de trabalhar em equipe, da disposição para procurar e aceitar críticas, da disposição para o risco, de saber comunicar-se, da capacidade de buscar conhecimentos (BRASIL, 2006, p. 30).

Quando nos voltamos para Alagoas, isto é, para o chão de nossa pesquisa, o sentido enquanto rumo e orientação não é menos exigente. Espera-se da Filosofia "a ruptura com o senso comum e com o dogmatismo, propiciando a abertura para o debate, a crítica, a manifestação da contradição no âmbito da relação entre o público e o privado, naquilo que é urgente para a construção da cidadania em Alagoas" (ALAGOAS, 2014, p. 120).

Os sentidos manifestos nesses documentos tendem para a presença de sentido do ensino de Filosofia, de acordo com o entendimento de sentido que aqui expomos. Entretanto, na prática e na própria história do ensino de Filosofia, os sentidos aparecem mais como negligência. Podemos dizer que há um paradoxo entre os discursos e as práticas do ensino de Filosofia, o que talvez torne ainda mais relevante refletir sobre os sentidos desse ensino.

\section{0 método fenomenológico na pesquisa}

A escolha pelo método fenomenológico aplicado à pesquisa se deu após as leituras feitas sobre metodologia de pesquisa, nas quais percebemos ser esse método o mais adequado para investigar o que nos propomos com este trabalho, isto é, os sentidos que alunos e professores possuem sobre o ensino de Filosofia no Ensino Médio. Conforme Moreira (2002, p. 108) “[...] o método fenomenológico enfoca fenômenos subjetivos na crença de que verdades essenciais acerca da realidade são baseadas na experiência vivida [...]. O que interessa é a experiência vivida no mundo do dia-a-dia". E é justamente na experiência de docentes e discentes que buscamos compreender os sentidos sobre o ensino de Filosofia.

Ao se investigar os sentidos é preciso ter consciência que esses fazem partem de uma experiência íntima, a qual o pesquisador só pode ter acesso a partir do que a própria pessoa fornece sobre o fenômeno em questão. Essa coleta de dados pode ser feita "por alguma forma de relato do sujeito da pesquisa, ou falando em uma entrevista, ou escrevendo de próprio punho" (MOREIRA, 2002, p. 103). Assim é preciso que as informações sobre o fenômeno partam dos próprios sujeitos. 
O método fenomenológico encontra suas raízes na Filosofia, com Edmund Husserl, no início do século XX. Entretanto, é preciso ter ciência de que a transposição do método para o contexto da pesquisa empírica implica em adaptações e concessões de rigor, conforme explica Moreira (2002, p.113). O que está no fim do processo é a descoberta das essências dos fenômenos estudados, além das reduções, entendendo que "[...] Os diversos aspectos da experiência comum a todos os participantes, constituir-se-ão na essência da experiência vivida" (MOREIRA, 2002, p. 115). E são esses aspectos comuns que desejamos ressaltar quanto ao ensino de Filosofia.

As diferenças entre o método fenomenológico e outros métodos de pesquisa são bem perceptíveis. Por exemplo, com relação ao problema da pesquisa, esse corresponde mais a uma inquietação do pesquisador em relação ao fenômeno. "Algo o incomoda, gerando uma tensão que o leva a buscar a essência do fenômeno. Fenômeno esse que, ao mesmo tempo em que lhe causa certa estranheza, também lhe é familiar, pois faz parte da realidade vivida" (GIL, 2010, p. 136). Com relação as hipóteses, também, nesse tipo de método elas não existem, uma vez que o problema se pauta nas dúvidas que o pesquisador têm, que ele deve responder a partir das repostas dos sujeitos da pesquisa.

Entre as variantes do método fenomenológico aplicado à pesquisa empírica, as semelhanças estão na coleta de dados e na apresentação dos resultados. A mais utilizada das técnicas para coleta de dados é a entrevista oral, "geralmente aberta, com poucos participantes - um a dez, geralmente, raramente mais que esse número, com a mediana por volta de seis a oito participantes" (MOREIRA, 2002, p. 118). Em nossa pesquisa utilizamos a entrevista semiestruturada, uma vez que essa permite mais liberdade por parte do entrevistado, ao mesmo tempo que garante que o pesquisador mantenha seu foco (GIL, 2010).

A variante de Colaizzi (1978), descrita por Moreira (2002) foi por nós escolhida para a realização dessa pesquisa Segundo essa variante, o primeiro passo consiste na leitura da descrição de cada informante, objetivando uma visão geral dos protocolos (descrições). Na sequência, procede-se a extração das assertivas significativas, o que nos permitirá ao fim dessa etapa ter em mãos um conjunto de declarações significativas de cada protocolo. Em seguida, passamos à formulação de significados, que consiste em buscar o que está implícito, entretanto, mantendo-se fiel ao que disse cada participante. Após a formulação de significados, seguimos com a organização dos significados em conjunto de temas, seguida de uma integração dos resultados em uma descrição exaustiva, isto é, uma descrição detalhada e analítica dos significados e ideias relativos a cada tema. Daí seguimos com a elaboração da estrutura essencial do fenômeno, uma espécie de síntese do que é comum a todos os participantes, concluindo com a validação da estrutura essencial, contrastando a descrição com as experiências vividas. 


\section{A compreensão dos sentidos na pesquisa empírica}

\section{O contexto da pesquisa}

A pesquisa que empreendemos teve sua motivação inicial na nossa prática docente. Ao findar de cada dia letivo, a questão do sentido que o ensino de Filosofia tinha para nós, enquanto professores e para aqueles com quem nos relacionávamos nessa prática permanecia presente em nós. Assim sendo, decidimos por tornar a inquietação da nossa experiência em uma pesquisa acadêmica que culminou nesse trabalho.

O nosso trabalho teve o seu desenvolvimento em duas escolas públicas da rede estadual de Alagoas, na cidade de Rio Largo. A escolha por essa localidade se deu pelo fato de já termos uma experiência enquanto docentes, no período de 2012 a 2014. O número de participantes da pesquisa, não foi definido a priori, posto que não é possível fazê-lo (GIL, 2010). Na escolha dos participantes alunos, levamos em conta como critérios a habilidade para se expressar verbalmente, bem como para perceber e expressar seus sentimentos interiores e emoções.

A escolha por desenvolver este trabalho com os professores se deu ao fato de considerarmos o professor como alguém que pensa sua própria prática, como afirma Lima (2010, p. 73):

[...] é preciso que se reconstrua a compreensão do trabalho do professor de filosofia, levando-se em consideração o professor como educador que pensa sua prática e direciona sua ação para a reestruturação de suas condições de trabalho, assumindo a atividade docente como prática transformadora.

Posto isto, consideramos essencial a participação dos professores de Filosofia em nossa pesquisa, uma vez que tivemos a oportunidade de pensarmos juntos a nossa prática docente. O professor é um sujeito que pensa - produz sentido - sobre sua própria prática, pois "É inegável que o próprio exercício docente confere novos sentidos, seja à formação inicial, seja à prática pedagógica, à profissionalização e até a própria vida pessoal do professor" (DIAS, 2008, p.3).

A escolha pela participação dos alunos na pesquisa, deu-se por compreendermos que, enquanto sujeitos envolvidos com o ensino de Filosofia, também são capazes de pensar, de produzir sentido sobre o que vivem nessa prática. Ademais, compreendemos a importância de ouvir a voz daqueles que são diretamente afetados por essa experiência a qual produz diversos efeitos sobre suas vivências.

Após nossa aprovação no processo de seleção do Programa de Pós-Graduação em Educação da Universidade Federal de Alagoas, tendo cumprindo os créditos em disciplinas, submetemos o nosso trabalho ao Conselho de Ética e Pesquisa da mesma universidade aos doze dias do mês de abril de 2017. Após rejeição por pendências, o submetemos novamente em 27 de maio do mesmo ano. Em 22 de junho recebemos o parecer apontando novas pendências, o que 
nos levou a submeter o projeto novamente em 6 de julho, obtendo a aprovação para iniciar a pesquisa no dia 10 de agosto do ano supracitado.

A pesquisa nas escolas teve início no dia 26 de setembro de 2017, momento em que foi realizado o primeiro contato com professores e alunos, a fim de estabelecer o clima de receptividade requerido nesta pesquisa (GIL, 2010, p. 138) e assegurar a confidencialidade dos dados, bem como obter a permissão para que as entrevistas fossem gravadas. As últimas entrevistas foram gravadas em 22 de novembro do mesmo ano.

As perguntas direcionadas aos professores foram as seguintes: a) Como a filosofia pode contribuir para a formação do jovem estudante?; b) O que te motivou a ser professor de filosofia?; c) Você acredita que os alunos se sentem motivados a estudar filosofia?; d) Como você utiliza o livro didático em sala de aula?; e) O que você pretende alcançar com o ensino de filosofia para os jovens?; e f) Como professor, qual o sentido de ensinar filosofia para os jovens?. Aos alunos, direcionamos as seguintes questões: a) Quais as contribuições que a filosofia tem proporcionado ao seu aprendizado?; b) Você sente alguma dificuldade ao estudar filosofia?; c) Existe alguma motivação para você estudar filosofia?; e d) Qual o sentido que possui o ensino de Filosofia para você?

Os dados foram colhidos por meio de entrevista semiestruturada. Escolhemos tal modelo de coleta por esse permitir maior liberdade por parte do entrevistado na oferta dos dados, bem como, permitir ao pesquisador manter seu foco. Procuramos ao máximo manter as entrevistas em um clima de tranquilidade, como uma conversa entre duas pessoas, por vezes com interferências nossas para entender melhor o que o participante da pesquisa estava dizendo.

A explicitação desses dados, conforme o critério da confidencialidade, será feita da seguinte maneira: as escolas serão tratadas aqui como "Escola A" e "Escola B", bem como as professoras, como "Professora A" e "Professora B" $\mathrm{Na}$ "Escola A" tivemos a participação de 4 alunas e 1 aluno, além de 1 professora; na "Escola B" tivemos 3 alunos, 2 alunas e 1 professora.

A seguir, vamos explicitar as assertivas significativas extraídas, os significados formulados, os temas organizados, a descrição dos resultados e as estruturas essenciais do fenômeno.

\section{As contribuições da Filosofia}

A pergunta pela contribuição da Filosofia para a formação dos jovens pode nos conduzir a outras perguntas por vezes incômodas como: para que serve a Filosofia? Qual o seu propósito? Para que Filosofia na escola? Perguntas incômodas porque nos retiram do lugar comum de nossas certezas e nos desafiam a rever, a lançar um novo olhar sobre o ensino de Filosofia. No entanto, o incômodo pode vir por razão da perversidade implícita no discurso de quem profere tais questões, afinal, se a Filosofia não tem com o que contribuir, por que se mantêm ainda no currículo? 
As justificativas para a estada do ensino de Filosofia no Ensino Médio se pautam, por vezes, em uma instrumentalização dela, colocando a cidadania, ou seu exercício, como o produto dessa relação entre a escola e essa prática do pensamento (GALLO, 2010). Isso seria o bastante? A Filosofia tem algo mais a oferecer aos jovens de nossos dias? Se tem, o que seria esse algo?

O questionamento que nos propomos nos leva a encarar outra questão: a perca de sentido da Filosofia, sobre a qual refletimos, de algum modo, em outro momento de nosso texto. A perca de sentido, enquanto cuidado, presente no discurso de gestores e coordenadores nas escolas, a qual cria uma hierarquização de disciplinas, pode ter suas raízes na falta de sentido, enquanto compreensão do que é a Filosofia e de sua contribuição.

A tentativa de situar a Filosofia no ambiente escolar, como uma disciplina do currículo, implica necessariamente nesse questionamento primeiro ao qual nos propomos (FAVARETTO, 2008). E o que pensam os professores e alunos a esse respeito? O que têm a dizer sobre as contribuições que a Filosofia pode e têm (ou não) oferecido à formação e ao aprendizado desses sujeitos envolvidos com essa prática?

As assertivas significativas que saltaram a nossa percepção durante a leitura dos protocolos de alunos e professores foram muitas. Uma vez que a questão possui o mesmo fio condutor, optamos por apresentar todas as assertivas em um único conjunto, independentemente de quem possa ter respondido.

O fazer refletir sobre o novo, o dissenso, o ver até que ponto é possível pensar diferente do que já se pensa ou saber diferente do que já se sabe aparecem aqui como a maior contribuição que a Filosofia pode oferecer aos jovens de nosso tempo. "A Filosofia é constante processo de criação. É fundamentalmente criação de novas interpretações e novos significados" (GHEDIN, 2009, p. 88), e como tal, pode oferecer esse novo olhar sobre a realidade.

O novo olhar sobre a realidade, o refletir sobre o novo, conduz-nos a pensar outras possibilidades existenciais, a perceber os diversos sentidos que a vida pode ter. Em uma perspectiva de uma educação fenomenológica, como pontuamos em outro momento de nossa discussão, essa reflexão sobre o novo pode contribuir para o respeito ao "Alther", ao Outro, ao diferente.

A contribuição para o pensar, a qual possui uma forte conexão com o refletir sobre o novo, aparece aqui como uma das contribuições mais destacadas pelos participantes de nossa pesquisa. Segundo Cerletti (2008, p. 41):

Ensinar filosofia é convidar a pensar. É convidar a compartilhar uma atividade que supõe um esforço, é certo, mas abre a enorme perspectiva de chegar a enfrentar-se com o novo. E quando se possibilita a novidade, quando aparece algo que antes não havia, em alguma medida, transformamos o mundo.

O pensar aparece como a possibilidade de confrontar-se com o novo. Se a filosofia pode contribuir dessa maneira na formação dos jovens de hoje, então, ela tem muito a contribuir, uma vez que o "ato de pensar como um 
processo de criação, de produção de novas formas de ser e de sentir o mundo, está distante da realidade dos alunos [...]" (BENETTI, 2007, p. 130). É preciso entender que aqui o pensamento não é tido como algo que simplesmente acontece, pelo menos não no sentido em que o pensar é apresentado, o ato de pensar precisa ser provocado.

O que funda o pensamento é a força de um encontro com algo que mexe e desassossega e, portanto, desencadeia o ato de pensamento. Isso porque, o pensamento não se dá pelo reconhecimento e pela identificação do objeto, mas a partir do arrombamento de algo da ordem da sensibilidade [...] Assim, só o que pode ser sentido no encontro com algo que sensibiliza o pensador a pôr um problema força-o a pensar o que ainda não foi pensado (BENETTI, 2007, p. 138).

O pensamento precisa ser provocado. E o ensino de Filosofia, segundo a experiência de quem está com ele envolvido, pode proporcionar essa provocação. Não queremos com isso assumir um discurso segundo o qual apenas a Filosofia seja capaz de provocar esse pensamento, mas sim, que ela também pode fazê-lo.

O ensino de Filosofia pode contribuir com a tomada de decisões. Por sua potência desestabilizadora que nos põe em um processo de busca incessante por respostas para as indagações de nossa existência, a Filosofia pode contribuir para que se tomem decisões mais acertadas, considerado os diversos aspectos da realidade, suas múltiplas dimensões.

"O buscar nos transforma, faz-nos mudar de atitude em relação ao que sempre fomos, revela nossas insatisfações, nos impulsiona a atingir uma nova visão das coisas" (FAVARETTO, 2008, p. 55). Mais ainda, ajuda-nos a pôr em questão o que recebemos de outros, que tornam o nosso pensamento mais dos outros do que próprio.

A Filosofia pode contribuir com a busca por saber mais. Em uma sociedade de massificação, na qual reina a inautenticidade, em que o ser-aí decai nas ocupações das coisas, em que os jovens são obrigados a serem isto ou aquilo, negando-lhes a possibilidade de escolha (SAYÃO, 2007, p.299), a Filosofia pode sim, educar para o pensamento autônomo.

Educar para o pensamento autônomo implica em rejeitar o consenso, que inibe o homem de ser ele mesmo, que o impede de ousar pelos caminhos do conhecimento [...]. Convivendo com a alteridade, aceitando a diferença, o ser humano pode visualizar novas perspectivas de transformação de si mesmo, do outro e do mundo (GONÇALVES, 2007, p. 351).

O pensamento autônomo se torna garantia deste visualizar o mundo de outra forma, como contribuição que a Filosofia pode oferecer, o que carrega uma potência ética, política e estética importante: conviver com as diferenças, transformar a própria vida, visualizar novas perspectivas de existência podem ser ferramentas importantes, ainda 
mais quando nossa sociedade atravessa um momento de extrema polarização dos discursos, a qual pode nos conduzir à retomada de antigos processos de barbárie e desumanização.

O cenário descrito nos conduz a pensar sobre mais uma contribuição que a Filosofia pode oferecer, segundo os sujeitos de nossa pesquisa: ajudar na argumentação e na defesa dos direitos. Tal contribuição, parece ser uma das mais importantes, segundo as Orientações Curriculares para o Ensino de Filosofia, "é a contribuição mais importante da Filosofia: fazer o estudante aceder a uma competência discursivo-filosófica” (BRASIL, 2006, p.30). Aqui, o exercício da cidadania, como contribuição, aparece de forma implícita.

A capacidade de argumentação é mais uma atitude necessária nos dias em que vivemos, dado a conjuntura atual de nossa sociedade. A proliferação das chamadas fake news, dos discursos inflamados de paixão, põem em xeque a própria razão, desafiando-nos a desenvolver a capacidade de um discurso construído de forma crítica e racional. E a Filosofia pode oferecer essa possibilidade.

O despertar da curiosidade e a obtenção de uma visão mais ampla sobre a realidade ainda apareceram como possíveis contribuições da Filosofia. A curiosidade que leva a busca incessante do conhecimento, da verdade, mostrase como importante no processo de filosofar, o que pode contribuir para se adquirir essa visão mais ampla, como já discutimos anteriormente.

As contribuições do ensino de Filosofia são diversas, conforme pontuaram os participantes de nossa pesquisa, as quais encontram fundamento na literatura já existente sobre o ensino de Filosofia, nos discursos de diversos pensadores e especialistas dessa prática pedagógica. Não podemos esperar que a Filosofia salve o mundo, atribuir-lhe algum poder redentor, mas podemos perceber o quanto ela pode ser importante para a formação dos estudantes de nossos dias.

\section{Dificuldades e motivações}

O ensino de Filosofia, por seu trato conceitual, pode apresentar dificuldades para quem decide trilhar os seus caminhos. Para os jovens do Ensino Médio, as dificuldades de leitura, de trato com os conceitos, podem ser muitas. Entretanto, as motivações para se estudar Filosofia, para estar com ela, para seguir em suas vias podem ser maiores.

A questão sobre as dificuldades e as motivações a respeito do ensino de Filosofia, dadas as respostas apresentadas, decidimos por refletir sobre elas em conjunto, uma vez que o que disseram os sujeitos de nossa pesquisa, sobre uma e outra, tem algo que as une.

A maioria dos entrevistados afirmaram não sentir dificuldade ao estudar Filosofia, o que à primeira vista pode parecer estranho. Porém, a resposta à segunda pergunta pode ser a chave para entendemos a primeira. Aqueles que 
disseram ter dificuldade apontaram: a linguagem usada pela professora, os conceitos difíceis da Filosofia ou, ainda, o incômodo provocado pela revisão do próprio pensamento diante de diversas questões.

A última dificuldade aqui apresentada parece ser vista de forma positiva pelos que se dedicam a estudar sobre o ensino de Filosofia. Assim dizem Aspis e Gallo (2009, p. 88) sobre a questão:

O professor de filosofia terá, isto sim, que deixar as coisas nubladas. Ele vai incomodar o aluno, se seu propósito é questionar. O professor, na fase de problematizar, deixará o aluno desconfortável, perplexo até, sensação já começada na sensibilização.

A Filosofia causa desconforto, desestabiliza-nos, retira-nos do comum da existência e nos põe na busca incessante pelo saber mais. Isso, de certo, causa desconforto, uma vez que pode abalar o edifício de certezas que o estudante traz consigo. Em nossa prática, não raras foram as vezes em que a violência, ainda que simbólica, se fez sentir por parte dos alunos, ao questionarmos suas certezas mais profundas.

As motivações também estão presentes no ensino de Filosofia. E a professora apareceu, para a maioria, como a maior fonte de motivação. Tal constatação nos leva a questionar o porquê dessas afirmações. Os alunos responderam que a professora ensina bem, tem uma aula legal, deixa um gostinho de quero mais etc.

As duas professoras participantes da nossa pesquisa possuem formação específica em Filosofia. A literatura por nós consultada sobre o ensino de Filosofia concorda que o profissional que esteja em sala de aula deve ter a formação específica na área em que atua. Ainda que não seja condição suficiente, é condição necessária a boa formação em Filosofia, para que se possa ter uma boa didática filosófica (BRASIL, 2006, p. 17).

A não dificuldade dos alunos, expressa acima, talvez - aqui trata-se de uma hipótese - a boa formação dos profissionais que estão com eles, ainda que se apresentem algumas lacunas, como a da linguagem conceitual utilizada. É importante insistir - ainda que em tempos de ameaça à continuidade do ensino de Filosofia no Ensino Médio - na formação específica daqueles que se dedicam a tal tarefa. "Não basta então o talento do professor se não houver igualmente uma formação filosófica adequada e, de preferência, contínua" (BRASIL, 2006, p. 17).

O cenário educacional atual, pelo menos em Alagoas, apresenta uma realidade diferente na qual profissionais não formados em Filosofia acabam por assumir o ensino nessa área. Não é uma questão de competência apenas, mas de familiaridade com os textos filosóficos e com os grandes temas da história da Filosofia.

A importância do professor, de como ele conduz seu trabalho, de como ele pode ser um fator de motivação para os seus alunos, para o estudo da disciplina ou área que está sob sua responsabilidade são grandes, a partir do que foi dito por nossos entrevistados. Pensar e repensar a própria prática, assim como a prática docente de forma abrangente 
é mais que necessário se queremos um ensino de qualidade, mesmo sabendo que não é condição exclusiva para tanto.

A curiosidade ou o conhecimento por si mesmo, por outro lado, foram postos também como motivação para se estudar Filosofia. Curiosidade e conhecimento possuem uma estreita relação, ao passo que é a curiosidade, o querer saber mais que possibilita o conhecimento, a busca de respostas. E isso precisa ser desenvolvido por meio da Filosofia. Assim as OCN's apontam a curiosidade e a busca pelo conhecimento como algumas das tantas capacidades a serem desenvolvidas pelo ensino de Filosofia no Ensino Médio:

Trata-se da criatividade, da curiosidade, da capacidade de pensar múltiplas alternativas para a solução de um problema, ou seja, do desenvolvimento do pensamento crítico, da capacidade de trabalhar em equipe, da disposição para procurar e aceitar críticas, da disposição para o risco, de saber comunicar-se, da capacidade de buscar conhecimentos (BRASIL, 2006, p. 30).

\section{0 ensino de Filosofia e seu sentido}

A última pergunta de nossa entrevista diz respeito aos sentidos sobre o ensino de Filosofia. Uma vez que a mesma pergunta foi dirigida a professoras e alunos, decidimos por trazer as respostas de forma conjunta.

A Filosofia, enquanto compreensão do mundo, aparece como a principal resposta entre os participantes. O sentido do ensino de Filosofia seria, então, fazer saber mais, saber as coisas, seria uma abertura para o conhecimento. Trata-se de ter aquele olhar agudo que não quer deixar nada sem rever (CERLETTI, 2008, p. 27-28). É aquela capacidade de buscar conhecimentos, como apontam as orientações oficiais para o ensino de Filosofia, já citadas aqui.

O ensino de Filosofia tem seu sentido como rumo, na perspectiva de que auxilia o estudante a crescer pessoalmente e a fazer a escolha certa. Se a Filosofia é capaz de proporcionar o conhecimento, o querer saber mais, essa abertura de horizontes, pode permitir ao estudante ter uma visão mais ampla da realidade, o que poderia permiti-lo, conhecendo mais, escolher de forma mais acertada.

O pensamento crítico, enquanto sentido da Filosofia na compreensão mais ampla da realidade, configura-se como um pensar livre e rigoroso. É este pensar que pode contribuir para se tomar as decisões mais acertadas na vida, o que nos remete aos sentidos expostos anteriormente. Há uma relação entre conhecimento, crescimento pessoal, escolha certa e pensamento crítico.

O conhecimento, por abrir o ser-aí à compreensão, possibilita o crescimento pessoal, uma vez que possibilita a percepção de outros aspectos da realidade. Na posse dessa visão mais ampla do mundo, das múltiplas possibilidades 
da existência, torna-se possível - ainda que não seja garantia - escolher de forma mais acertada. E essa visão de mundo mais ampla só é possível quando o ser-aí se apropria do pensamento crítico, do autêntico filosofar.

Conforme Ghedin (2009, p. 49)

Filosofar, na conjuntura atual, é desmistificar as amarras do mundo que nos impedem de ser autenticamente humanos. Significa recriar a realidade, o mundo, a compreensão da existência a fim de libertar-nos de todas as condições que nos privam de manifestar a verdade do ser.

A descoberta do novo, daquilo que antes não se via, daquilo que não estava manifesto aparece novamente aqui. É na multiplicidade de sentidos que podemos recriar a realidade e a compreensão de que a existência é bem mais do que somos condicionados a acreditarmos. Ser autenticamente humanos: mais uma contribuição que o ensino de Filosofia pode oferecer aos nossos jovens de hoje.

\section{Outras discussões sobre o ensino de Filosofia}

As entrevistas por nós realizadas trouxeram outras questões exclusivas para os professores. Aquelas que dizem respeito à metodologia, ao uso do livro didático e ao que as professoras pretendem alcançar com o ensino de Filosofia. Tais questões foram postas nas entrevistas com o intuito de conhecer sobre a prática docente de nossas entrevistadas.

A metodologia utilizada, segundo as respostas da Professora A e da Professora B, coincidiu muito. Ambas apontaram o uso de slides, vídeos, músicas, poemas, textos filosóficos, seminários, produções textuais e do livro didático em sala de aula como aquilo que mais utilizam no ensino de Filosofia. A utilização desses recursos, principalmente dos vídeos, músicas e poemas é feita objetivando introduzir os alunos nos temas de estudo.

A utilização dos recursos citados acima não é garantia, por si só, de um autêntico ensino de Filosofia. Além da formação específica - já defendida de maneira categórica - é preciso que o professor seja capaz de convidar os alunos à prática da reflexão (BRASIL, 2006, p. 37). As orientações defendem o primado do texto filosófico, o qual é utilizado pelas professoras, atitude que será mais coerente para quem possui essa familiaridade com o texto e com a história da filosofia.

A garantia da familiaridade e com a história da filosofia requer do professor uma tradição de leitura consolidada, a continuidade de pesquisa e de formação especificamente filosóficas, além de evitar a gratuidade da opinião (BRASIL, 2006). Embora seja desejável e prazeroso o uso dos recursos utilizados pelas professoras, nada disso pode substituir o contato com o texto filosófico. 
A utilização do livro didático é feita de forma periférica, recorrendo-se a esse material como auxiliar para a realização dos exercícios que esses propõem. A Professora B justificou esse uso devido ao pouco tempo que é disponibilizado para a disciplina. Já a Professora A justificou como sendo uma escolha pessoal, por não gostar do livro, preferindo utilizar o que ela chamou de "recursos próprios", como os vídeos, músicas, poemas.

O livro didático pode auxiliar, porém,

[...] o professor que estiver bitolado ao manual está na contra mão das orientações curriculares [...] A ideia é que ele seja capaz, com a sua formação, de fazer um projeto próprio, porque somente assim vai realizar em sala de aula uma experiência filosófica autêntica, sempre diferente de sala para sala, diferente de professor para professor (CARVALHO; SANTOS, 2010, p. 36).

A criatividade é exigência para o professor de Filosofia. Como um "criador de conceitos", deve ele também ser capaz de criar e utilizar-se de materiais, de recursos criados por ele mesmo. Não estamos condenando o uso do livro didático, mas sugerindo que ele não deve ser o centro do ensino de Filosofia.

A questão sobre o que se pretende alcançar com o ensino de Filosofia teve como respostas: "um novo sistema", "a busca de compromisso com um futuro melhor", "perceber a verdade", "o conhecimento", "a formação de cidadãos pensantes", "saber argumentar". Alguns dos objetivos esperados com a prática do ensino de Filosofia apareceram como resposta ao sentido que se tem dessa prática. O conhecimento e a percepção da verdade contribuem para a formação de cidadãos pensantes capazes de argumentar, de oferecer razões e justificativas para seus posicionamentos, podendo levá-los a buscar um compromisso com um futuro melhor e, assim, instaurar um novo modo de vida e de existir.

A compreensão do ensino de Filosofia nos ajuda a perceber as diversas e imensas possibilidades que essa prática possui. No entanto, é preciso cuidar para que não se superestime a Filosofia, a ponto de colocá-la como "redentora da humanidade" ou algo equivalente. Como apresentado em nosso texto, são possibilidades as quais, devido diversos fatores, podem ou não ser efetivadas.

A filosofia e seu ensino possuem uma responsabilidade

[...] a responsabilidade da filosofia na sociedade e na escola permanece a mesma desde suas origens: contribuir com o processo de construção da autonomia crítica dos cidadãos, ensinando às novas gerações a repensar continuamente o mundo com suas próprias cabeças, a abrir espaços para sair de todas as cavernas, de todos os entraves à apreensão livre e crítica do viver (CORNELLI; CARVALHO; DANELON, 2010, p. 12). 
O repensar continuamente o mundo, abrir novos espaços, a apreensão livre e crítica do viver coadunam com o que foi dito até aqui sobre o sentido do ensino de Filosofia. Entretanto, não podemos enclausurar os sentidos. É possível encontrar outros sentidos e mais sentidos diferentes do que até aqui expomos. Pensar o sentido do ensino de Filosofia é nunca deixar de pensar e repensar esses sentidos, em uma prática constante, como é próprio do filosofar.

\section{Considerações finais}

Por meio de nossa pesquisa tivemos a oportunidade de constatar o quão difusos são esses sentidos, mas que há sentidos para essa prática, evidenciados pelos próprios sujeitos do processo. A Filosofia faz refletir sobre o novo, abrindo um campo de perspectivas, de horizontes antes desconhecidos. "É constante processo de criação" (GHEDIN, 2009, p. 88). É por essa abertura ao novo que ela pode proporcionar o saber mais.

A reflexão sobre o novo, o novo olhar sobre a realidade pode abrir o ser-aí a multiplicidade de suas possibilidades existenciais, o que pode contribuir, e muito, para que cada existência seja única, que cada singularidade seja permitida em meio a pluralidade de sons, de cores, de sabores, de amores, de credos. Há uma dimensão ética importante no sentido do ensino de Filosofia e essa é uma das razões pelas quais devemos defender o acesso dos jovens ao seu ensino.

A Filosofia pode contribuir com o pensar, pode desenvolver esse pensar, afinal, é isso que é ensinar Filosofia: convidar a pensar (CERLETTI, 2008, p.41). Não se trata aqui do pensar como algo natural que simplesmente acontece, mas como algo que é provocado, instigado. O pensar é um encontro que nos desestabiliza, que nos retira do nosso lugar comum e nos faz ir além do que pensávamos saber.

A potência de desenvolvimento do pensamento proporciona ao homem tomar decisões mais acertadas, uma vez que o faz ter um conhecimento mais amplo da realidade que o cerca em suas múltiplas dimensões. Além disso, o bem pensar pode contribuir para o desenvolvimento de uma argumentação sólida e consistente, tão necessária nos dias atuais em que os discursos estão tão polarizados e ameaçam a própria existência humana ao defenderem processos de barbárie e desumanização do humano.

A pesquisa realizada permitiu, ainda, que tocássemos em um ponto importante: a necessidade da formação específica para o exercício da docência de Filosofia no Ensino Médio. Os documentos oficiais a exigem, a experiência das professoras e dos alunos parecem convergir nesse ponto, os especialistas do ensino de Filosofia também o defendem. Mesmo que essa formação não seja garantia de um ensino de Filosofia pleno, ela é condição necessária e não deve ser negligenciada. 
O objetivo maior de nossos estudos, além do objetivo da pesquisa que foi o de investigar os sentidos a respeito do ensino de Filosofia, é contribuir com a formação de novos professores de Filosofia e com a reflexão da prática daqueles que já atuam neste ensino. Muitos desafios se impõem a nós professores. Além da ameaça constante que paira sobre a permanência do ensino de Filosofia no Ensino Médio, ainda parece-nos ser exigido de nós uma justificação para que a Filosofia continue nos currículos dos anos finais da educação básica.

A compreensão dos sentidos sobre o ensino de Filosofia nos possibilita entender as diversas e imensas possibilidades que essa prática possui, possibilidades que podem ou não acontecer, por causa de diversos fatores. No entanto, a Filosofia possui uma responsabilidade, qual seja a de ensinar a repensar continuamente o mundo, para que se pense com a própria cabeça, de maneira livre e autônoma.

O sentido do ensino de Filosofia, diante de tudo o que foi exposto, está em fazer com que o ser humano seja plenamente ele mesmo, capaz de escolher, de dialogar e de construir um mundo mais aberto ao Outro, mas não só, uma vez que os sentidos são difusos. Afirmamos, então, que outros sentidos sejam possíveis. Nos coloquemos no caminho do pensar e repensar continuamente nossa prática enquanto professores de Filosofia, a fim de que possamos contribuir para a plena humanização dos jovens de nossos dias.

\section{Referências}

ALAGOAS. Secretaria de Estado da Educação e do Esporte - SEE. Referencial curricular da educação básica da rede estadual de ensino de Alagoas: ciências humanas. Maceió: Imprensa Oficial, 2014. https://doi.org/10.15687/rec.2015.v8n3. 453470

ASPIS, Renata Lima; GALLO, Silvio. Ensinar filosofia: um livro para professores. São Paulo: Atta Mídia e Educação, 2009.

BENETTI, Cláudia Cisiane. "Ensinar a pensar no contexto do ensino de Filosofia: um estudo com Gilles Deleuze". In: SARDI, Sérgio Augusto; SOUZA, Draiton Gonzaga de; CARBONARA, Vanderlei. (org.). Filosofia e Sociedade: perspectivas para o ensino de filosofia. Ijuí: Ed. Unijuí, 2007. p. 129-141. (Col. Filosofia e ensino, v. 11). https://doi.org/10.31496/rpd.v16i35.1084

BRASIL. Ministério da Educação. Secretaria de Educação Básica. Orientações Curriculares Nacionais para o Ensino Médio, v. 3. Ciências Humanas e suas tecnologias. Brasília, DF, 2006.

CARVALHO, Marcelo; SANTOS, Marli dos. “O ensino de Filosofia no Brasil: três gerações”. In: CORNELLI, Gabriele; CARVALHO, Marcelo; DANELON, Márcio (org.). Filosofia: ensino médio. Brasília: Ministério da Educação, Secretaria de Educação Básica, 2010. p. 13-44. (Col. Explorando o Ensino; v. 14). https://doi.org/10.5902/1984644430328 
CERLETTI, Alejandro A. "Ensinar Filosofia: da pergunta filosófica à proposta metodológica”. In: KOHAN, Walter O. (org.).

Filosofia: caminhos para seu ensino. Rio de Janeiro: Lamparina, 2008. p. 19-43.

CORNELLI, Gabriele; CARVALHO, Marcelo; DANELON, Márcio (org.). Filosofia: ensino médio. Brasília: Ministério da Educação, Secretaria de Educação Básica, 2010. (Col. Explorando o Ensino; v. 14).

DIAS, Isaltino. A Filosofia no Ensino Médio: sentidos no exercício da docência”. [S. l.; s. n.], 2008. Disponível em: http://www. portalanpedsul.com.br/admin/uploads/2008/filosofia_e_educacao/Trabalho/12_19_07_A_filosofia_no_ensino_medio__ sentidos_ do_exercicio_da_docenc.pdf. Acesso em: 1 dez. 2015. https://doi.org/10.17771/pucrio.āacad.29802

FAVARETTO, Celso. "Filosofia, ensino e cultura". In: KOHAN, Walter O. (org.). Filosofia: caminhos para seu ensino. Rio de Janeiro: Lamparina, 2008. p. 43-53.

GALLO, Silvio. "Ensino de Filosofia: avaliação e materiais". In: CORNELLI, Gabriele; CARVALHO, Marcelo; DANELON, Márcio (org.). Filosofia: ensino médio. Brasília, DF: Ministério da Educação, Secretaria de Educação Básica, 2010. p. 159-170. (Col. Explorando o Ensino, v. 14). https://doi.org/10.5902/1984644430328

GHEDIN, Evandro. Ensino de Filosofia no Ensino Médio. 2. ed. São Paulo: Cortez, 2009.

GIL, Antônio Carlos. Como elaborar projetos de pesquisa. 5. ed. São Paulo: Atlas, 2010.

GONÇALVES, Rita de Athayde. Interlocução entre o pensamento complexo e a Filosofia como disciplina escolar. In: SARDI, Sérgio Augusto; SOUZA, Draiton Gonzaga de; CARBONARA, Vanderlei (org.). Filosofia e Sociedade: perspectivas para o ensino de filosofia. Ijuí: Ed. Unijuí, 2007. p. 341-353. (Col. Filosofia e ensino). https://doi.org/10.31496/rpd.v16i35.1084

HEIDEGGER, Martin. Ser e Tempo. 15. ed. Petropólis: Vozes, 2005.

LIMA, Walter Matias. O Ensino de Filosofia no Ensino Médio: problematizando a cidadania e a formação docente. Debates em Educação, Maceió, v. 2, n. 4, p. 65-78, 2010.

MOREIRA, Daniel Augusto. O método fenomenológico na pesquisa. São Paulo: Pioneira Thomson, 2002.

RODRIGUES, Valter Ferreira. O ensino de Filosofia como experiência crítico-criativa do filosofar: limites e possibilidades. 2014. 233 f. Tese (Doutorado em Educação). Programa de Pós-Graduação em Educação/Universidade Federal da Paraíba, João Pessoa, 2014. https://doi.org/10.29280/rappge.v4i2.5847

SAYÃO, Sandro Cozza. “A educação e a necessidade de novos territórios existenciais ao humano". In: SARDI, Sérgio Augusto; SOUZA, Draiton Gonzaga de; CARBONARA, Vanderlei. (org.). Filosofia e Sociedade: perspectivas para o ensino de filosofia. Ijuí: Ed. Unijuí, 2007. p. 295-307. (Col. Filosofia e Ensino). https://doi.org/10.18226/21784612.v24.e019032 
SODELLI, Marcelo. Sobre o sentido de educar. Aprender: Caderno de Filosofia e Psicologia da Educação, Vitória da Conquista, n. 10, p. 203-222, jan./jul. 2008. https://doi.org/10.22481/aprender.v0i17.3000

Recebido em: 12/1/2019.

Aprovado em: 20/12/2019

Publicado em: 17/4/2020.

\section{Endereço para correspondência}

Williams Nunes da Cunha Junior

Universidade Federal de Alagoas

Av. Lourival Melo Mota, s/n, Centro de Educação - Cidade Universitária

57072-970, Maceió, AL, Brasil

\section{Autor:}

Williams Nunes da CUNHA Junior

Mestre em Educação pela Universidade Federal de Alagoas (UFAL), Maceió, AL, Brasil. Professor Assistente (Substituto) na Universidade Federal de Alagoas (UFAL).

Orcid: http://orcid.org/0000-0002-6528-8880

E-mail: williamsjr_cmf@hotmail.com 